\title{
This is my unit: ICU, Svendborg Hospital, Denmark
}

Lone Juhl Christensen, RN; Master of Clinical Nursing), Intensive care nurse, Svendborg Hospital, 5700 Svendborg, Denmark

Key Words: Denmark intensive care unit nursing

E-mail: lonejuhl@gmail.com

\section{ESPAÑOL}

Esta es mi unidad: UCI, Hospital Svendborg, Dinamarca

Palabras clave

Dinamarca, unidad de cuidado intensivo, enfermería

Resumen

Este artículo describe una unidad de cuidado intensivo en Dinamarca.

La unidad de cuidado intensivo está ubicada en uno de los hospitales más pequeños de Dinamarca, en Svendborg, en el sur del país.

Lone Juhl presenta su perspectiva personal.

\section{SUMMARY}

- $\quad$ This paper describes an intensive care unit in Denmark.

- The intensive care unit is based in one of Denmark's smaller hospitals, in Svendborg, which is in the south of the country.

- Lone Juhl presents her personal perspective.

\section{INTRODUCTION}

I work in the intensive care unit (ICU) at Svendborg Hospital, which is in the south of Denmark. The hospital is a public hospital, and receives patients from the surrounding area, which cover a radius of 50 kilometers, and includes the surrounding islands. The hospital has an emergency ward, surgical wards with abdominal and orthopedic surgery, and medical wards such as cardiology, endocrinology and geriatrics. The hospital one of Denmark's smaller hospitals, and is administratively affiliated with the University Hospital Odense, which is about 50 kilometers away.

\section{THE UNIT}

The patients who are admitted to the ICU are a mixture of surgical and medical patients. Typically, the surgical patients are admitted due to complications after abdominal surgery, and many of our medical patients are admitted with with chronic obstructive pulmonary disease or alcohol abuse, and require mechanical ventilation. In addition, we admit patients with trauma, H1N1, pneumonia or patients who require close observation because they are respiratory or circulatory unstable.
The unit admits about 550 patients per year, and our average ICU length of stay is 3.4 days. However, although most patients have a relatively short stay, we have some patients who remain with us for many months. The average age of the patients is 65 years, and the numbers of patients who are more than 75 years old are increasing. Our overall ICU mortality is around $18 \%$. The cost per patient per per day in our ICU is estimated to be between $€ 2000-2700$.

Most of our intensive care patients who are intubated are not sedated, and are awake during the day. If we are afraid that they cannot cooperate and accept the tube, we will use sedation, but we rarely have any accidental extubations. When the patient is stable and recovering but still intubated, we try very hard to orientate them to reality. We talk to them, help them sit on the bedside or stand on their feet. If they are to weak, we will lift them into a chair, so they are assisted to get out of bed and sit in a chair twice a day. We guide them to take part in daily things such a combing hair, tooth brushing and watching television.

Almost all the patients receive their nutrition via a nasal feeding tube. When this is not possible, we provide parenteral nutrition. The patients who have a tracheotomy can drink and some times eat.

If a patient needs special observation and care after they have been extubated, they stay in our unit in an 'intermediate' bed.

\section{The nurses}

There are 60 nurses and 10 nursing assistants in our unit. About 48 nurses have undertaken specialist inyensive care nursing education. In Denmark, this is a 2-year training program following nursing qualification (which is 4 years). During the 2-years program the nurse goes to another ICU for 3 months and to another recovery ward for 6 weeks. The purpose of this is to see what goes on in other hospitals, see how things are done and maybe also have the opportunity to learn another highly specialised area such as paediatric intensive care, thoracic intensive care or neurological intensive care. In the training to become an intensive care nurse, the nurse also has an 8-week theoretical program, which concludes with an examination. At the end of the two-year training period, the nurse has to write a paper where the purpose is to design a research project to address a nursing problem.

We would like all ICU nurses to undertake specialist education, and every year four nurses are supported by the ICU on the program. When nurses are trained as intensive care nurses, we expect them to be able to identify and start treatment in acute situations until the doctor arrives and provide care to all intensive care patients. The education program is described in full on the following website: http://www2.dsr.dk/msite/text.asp?id=51\&TextID=13300\&ShowSub $s=1 \&$ ShowSubID $=11044$

The nurses who work in ICU must also supervise nurse students. 
In our ICU one specially educated nurse fulfils the lead role. Nurse students are seconded to the ICU for about three months, and sometimes we have international students as a part of an exchange program. Also, we regularly send nurses to other units for special intensive care training and host nurses from other units during their training program. While they are with us we provide training and education for them. Almost all nurses in the unit have teaching skills to provide the education/training for these nurses.

Nurses work 8.25 hour shifts over a 37 -hour week. At weekends nurses are able to do 12-hour shifts, which means they only have to work every fourth weekend. If they prefer to work 8.25 shift they must work every other weekend.

\section{Nursing care and management}

In the ICU we work one nurse to one patient. We have rooms with two patients, which means that during day and evening shifts there are always two nurses working together. We help each other when we have to turn the patients over or to lift the patient to a chair. If the patient is going to stand on his feet and maybe walk one or two steps, while intubated, we get the help of a physiotherapist and two porters. When we have coffee breaks and lunch, we also look after each other's patient.

Whenevr possible, we allocate the patient a contact nurse. The aim is for this nurse to be the main contact to relatives. They make a summary every week about what plans we have for the patient, how he is doing, what he has achieved et cetera. But because of the many shifts, and with nurses' days off, it can sometimes be difficult to find a nurse who can be the contact nurse. We try working with that, because we find it is the best way to maintain continuity for patients, the next of a kin, and nurses.

The nurses write in the nursing record in the patients' electronic medical record, called EPJ. We do not have much "paper" according the patient, or not much paper at all. Doctors and nurses writes in the electronic medical record the EPJ, and answers from blood tests and so forth are sent to that EPJ. That is most of the time very helpful, the records never disappear, several people can read and write in the same record at the same time. Rarely we have problems were the system is down, and that is an inconvenience.

\section{Multi-disciplinary team members}

In ICU we work together with other staff such as anaesthetists, physiotherapists, laboratory technicians, and X-ray technicians. The doctors stay in the unit most of the day, and it is always possible to get hold of them. They do a ward round in the daytime and again in the evening. At the ward round the doctor and the nurse discuss each patient's problems, and a plan will be made. Apart from the round, the doctors are available in the ICU all the time.

Physiotherapists visit the unit every day apart from Sunday. They do exercises with the patients, and help the stable patients to sit at the bedside or even stand on their feet.

Some of the patients have relatives who stay in the ICU most of the day, and sometimes they want to stay overnight. It is possible for them to have a small room, if the patient is critically ill. We do not have visiting hours; relatives can come and go as they like, but we do try to close for visitors around noon for a couple of hours, to make sure the patients can get some rest. Our policy is that relatives are good for the patients, and they are welcome to visit around the clock or phone any time.

\section{Research and development activity}

In ICU we are currently working very hard on quality of care. There is a national directive for all hospitals in Denmark to conduct quality activities according to 'The Danish Quality Model'. There must be quality care in all areas: quality in the way the nurses and doctors are keeping their skills up to date, quality in treatment, and so forth. The main focus is on patient safety, to assure that patients get the best possible treatment, by well-educated people, with well kept equipment, all the time. We regularly do audits to make sure everything is implemented. To see "if we do what we say we do", people are asked questions, and are required to demonstrate their knowledge, or to identify where they can find information about it. This is a process that takes very much time and many resources, and we hope patients will benefit from it. The benefit for staff is that we do get to be very aware of how important it is to have guidelines for many things, so treatment is not only depending of who is working on a particular day.

In our ICU we are doing a nurse-led project with patients who have been intubated for more than 72 hours. We do a follow-up with them, and invite them to a talk/interview two months after they leave ICU. This project will run for two years, after which we will analyse our data to decide whether to run it permanently. The project is very interesting. Seeing the patients again after their recovery is good for the nurses and also very important. Often nurses do not know what happens to patients after they leave the ICU, whether they survive or die. But this project motivates us to see that all our efforts ares worthwhile. It is also very interesting to hear former patients talk about their experiences in the ICU. Sometimes they have had hallucinations and delusions, and sometimes they can describe factual things they have seen or heard. This is very informative.

The ICU has a lot of different interest groups. Some are working with issues such as introduction of new employed nurses, introduction of nurses starting their intensive specialization, nutrition of patients, mobilisation, hygiene, obese patients (which are increasing), air mattresses, and security when transferring patients. At the moment our new challenge is the introduction of a new electronic patient record, which will give us the opportunity to search for the patients' other hospitalisations.

Because we are not a university hospital, research is not a part of daily life in the unit, however much research is done in the cardiology ward, which has a professor.

Our ICU is a very good place to work, from my point of view. The nurse-patient ratio is good, which gives a feeling of being able to do a good job. The staff turnover is low, which means that there are many experienced nurses, and a lot of them are able to participate in training new staff. There is a great deal of responsiveness to ideas that can contribute in developing of the ward.

This is my unit. If you would like to know more, you are more than welcome to contact me. 